\title{
Aplicação de ferramentas de avaliação de risco à saúde humana em águas subterrâneas contaminadas com organoclorados
}

\author{
Application of human health risk assessment tools to \\ groundwater contaminated with organochlorines
}

\author{
Mariana Barbosa Druszcz ${ }^{1}$ (D) Jörg Wolfgang Metzger², Marielle Feilstrecker ${ }^{1}$ \\ ${ }^{1}$ Universidade Federal do Paraná, Curitiba, PR, Brasil Email: marianadruszcz@gmail.com; Email: \\ mariellefr@gmail.com \\ 2Universität Stuttgart, Stuttgart, Alemanha Email: joerg.metzger@iswa.uni-stuttgart.de
}

\begin{abstract}
Como citar: Druszcz, M. B., Metzger, J. W., \& Feilstrecker, M. (2020). Aplicação de ferramentas de avaliação de risco à saúde humana em águas subterrâneas contaminadas com organoclorados. Revista de Gestão de Água da América Latina, v17, e4. https://doi.org/10.21168/rega.v17e4
\end{abstract}

RESUMO: A avaliação de risco à saúde humana é uma importante etapa do gerenciamento de áreas contaminadas e visa reduzir custos da remediação. Atualmente, não há estabelecida em âmbito nacional uma ferramenta específica para a determinação dos riscos causados pela exposição a contaminantes e das metas para a fase de intervenção. Neste contexto, o objetivo deste estudo foi determinar se há uma diferença objetiva no resultado de uma avaliação ao aplicar uma ferramenta em detrimento a outra. Foram avaliadas as Planilhas da CETESB e o software RISC5. Além disso, também buscou-se identificar as possíveis especificidades no uso de cada instrumento ao longo do desenvolvimento da avaliação a fim de majorar o conhecimento sobre cada sistema. Para tanto, foram realizadas simulações de avaliações de risco aplicando dados reais de um terreno onde o aquífero está contaminado com compostos organoclorados. Este estudo concluiu que as versões mais atuais das ferramentas disponibilizam uma gama diferente de cenários de exposição, modelos matemáticos, informações toxicológicas e ainda possuem diferentes níveis de flexibilidade para inserção de dados personalizados. Por fim, verificou-se que conforme o modelo conceitual da área e substâncias de interesse objetos de avaliação de risco à saúde humana, a escolha de determinada ferramenta pode influenciar no resultado final da avaliação, inclusive nas etapas seguintes do gerenciamento de áreas contaminadas.

PALAVRAS CHAVE: Análise de Risco à Saúde Humana, Aquífero Livre, Inalação de Vapores, Tetracloroetileno, Tricloroetileno, brownfield.

ABSTRACT: Human health risk assessment is an important step in the management of contaminated areas (brownfields) and aims to reduce remediation costs. Currently, there is no mandatory tool to be used for determining the risks caused by exposure to contaminants and target concentrations for the intervention phase. In this context, the aim of this study was to determine if there is an objective difference in the outcome of a risk assessment study by applying one tool over another. The CETESB Spreadsheets and the software RISC5 were evaluated. In order to increase knowledge about each system, in addition, this study also sought to identify possible specificities in the use of each instrument throughout the development of the risk assessment. The methodology involved simulations of a risk assessment with the application of real data from a land where the aquifer is contaminated with organochlorine compounds. This study concluded that the most current versions of the tools provide a different range of exposure scenarios, mathematical models, toxicological information and even have different levels of flexibility for custom data entry. Finally, it was found that according to the conceptual model of the area and substances of interest that are objects of a human health risk assessment study, the choice of a particular tool can influence the final outcome of the evaluation, including the following stages of the management of brownfields.

KEYWORDS: Human Health Risk Assessment, Unconfined Aquifer, Vapors Inhalation, Tetrachloroethylene, trichloroethylene, brownfield. 


\section{INTRODUÇÃO}

As áreas contaminadas existentes no Brasil são consequência do modelo de industrialização e expansão urbana das décadas passadas, quando a preocupação com o meio ambiente e o controle da poluição não eram importantes. Apenas quando a qualidade de vida da população passou a ser diretamente afetada, normativas sobre o tema foram criadas (Federação das Indústrias do Estado de Minas Gerais, 2017). Além de ocasionarem riscos à saúde, as propriedades contaminadas também podem ser consideradas um problema para o planejamento e desenvolvimento urbano da cidade (Grimski, 2004). 0 estado de São Paulo foi o pioneiro no país ao disciplinar legalmente o tema de áreas contaminadas, e o primeiro a publicar um cadastro de áreas contaminadas (Moraes et al., 2004). As normativas estaduais paulistas neste campo ainda hoje são as precursoras, sendo utilizadas como referências para outros estados, na formulação de novas diretrizes regionais e quando ainda não há procedimentos estabelecidos.

Atualmente não existe um cadastro com informações sobre as áreas contaminadas existentes em todo o país. Apenas são reunidas as informações disponibilizadas pelos estados onde o gerenciamento de passivos está mais avançado, como São Paulo, Rio de Janeiro e Minas Gerais. Estima-se que existam pelo menos seis mil áreas em todo o território nacional, sendo que os principais compostos identificados são solventes aromáticos, hidrocarbonetos policíclicos aromáticos (HPA), metais, solventes halogenados, derivados de petróleo e pesticidas (Teixeira et al., 2016; Araújo-Moura \& Caffaro Filho, 2015; Companhia Ambiental do Estado de São Paulo, 2015).

A identificação dos solventes halogenados organoclorados tetracloroeteno (PCE) e tricloroeteno (TCE) no ambiente são de grande preocupação devido a suas características físico-químicas e biológicas que resultam em um comportamento diferenciado nas matrizes ambientais e uma toxicidade elevada ao ser humano. Esses produtos são largamente empregados em processos de limpeza de peças metálicas e na lavagem a seco em lavanderias industriais e de pequeno porte. Eles são compostos de fase não aquosa, mais densos que a água, de baixas viscosidade e tensão superficial, o que faz com que atinjam camadas mais profundas e de difícil acesso no aquífero. Também apresentam baixas solubilidade e degradabilidade, propriedades que fazem com que, mesmo após décadas de um evento de contaminação ou aplicações de diferentes técnicas de remediação, esses compostos ainda permaneçam como fontes ativas. Por fim, são voláteis e altamente tóxicos aos seres humanos, e dessa forma ainda que em pequenas concentrações no ar ambiente podem acarretar aumento do risco de desenvolvimento de células carcinogênicas (Pankow \& Cherry, 1996; Agency for Toxic Substances and Disease Registry, 2020a, 2020b).

A Resolução CONAMA N.. 420/2009 (Brasil, 2009) foi a primeira normativa jurídica federal a tratar especificamente da qualidade de solo juntamente com a de água subterrânea, alinhando diretrizes para o gerenciamento de áreas onde essas matrizes sejam consideradas contaminadas (Araújo-Moura \& Caffaro Filho, 2015). Além desta, outras referências como as normas técnicas disponíveis pela Associação Brasileira de Normas Técnicas (ABNT) e dispositivos legais de outros estados e municípios devem ser consultados nas regiões carentes de regulação específica (Moraes et al., 2014).

O procedimento para o gerenciamento de áreas contaminadas segue etapas sequenciais e correlacionadas (Figura 1), visando otimizar recursos financeiros e técnicos (Companhia Ambiental do Estado de São Paulo, 2013). Entre cada etapa, as informações disponíveis sobre a configuração ambiental e processos naturais da área são sintetizadas em um modelo conceitual de exposição (MCE) que apresenta os possíveis caminhos de transporte dos contaminantes, desde suas fontes até os potenciais ou efetivos receptores expostos. O MCE contempla cenários de exposição hipotéticos ou reais, além de atuais ou futuros, são apresentados na forma escrita ou gráfica e seu nível de complexidade aumenta conforme informaç̧ões adicionais sobre a área são obtidas (Associação Brasileira de Normas Técnicas, 2013b; Companhia Ambiental do Estado de São Paulo, 2017; Companhia Ambiental do Estado de São Paulo \& Deutsche Gesellschaft für Technische Zusammenarbeit, 2001). 


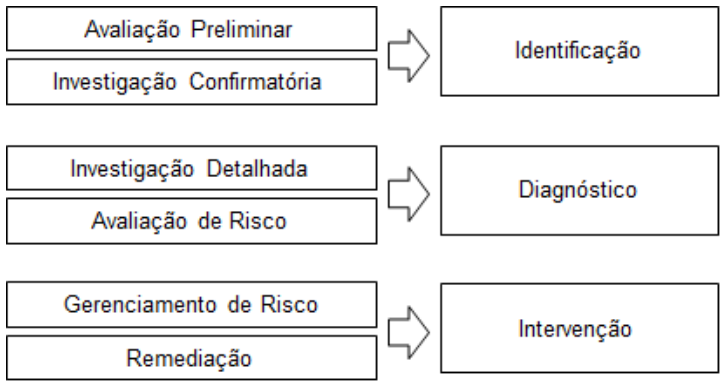

Figura 1. Etapas do gerenciamento de áreas contaminadas. Fonte: Adaptado de Brasil (2009).

A avaliação de risco é a fase na qual são identificados, avaliados e quantificados os riscos à saúde humana causados pela exposição a substâncias químicas presentes no meio físico (Associação Brasileira de Normas Técnicas, 2013a; Brasil, 2009). Esta avaliação começou a ser aplicada em áreas contaminadas por volta dos anos de 1980, nos Estados Unidos, visando auxiliar no processo de priorização de áreas para remediação. Dessa maneira, os recursos financeiros do programa Superfund do governo americano foram aplicados em áreas com maiores riscos à população (Song, 2004).

Os princípios e procedimentos para a realização de uma avaliação de risco foram publicados pela United States Environmental Protection Agency (1989) no documento intitulado "Risk Assessment Guidance for Superfund" (RAGS). Posteriormente, em 1995, a American Society for Testing and Materials (ASTM) publicou a norma ASTM E1739 com a mesma metodologia denominando-a de Risk Based Corrective Action (RBCA). Assim passou a ser adotada em áreas contaminadas além daquelas abrangidas pelo programa Superfund. e em diversos países (Cunha, 2012; United States Environmental Protection Agency, 1989; Dias et al., 2001).

A ASTM E1739, entretanto, tinha como objetivo as contaminações de hidrocarbonetos derivados de petróleo. A norma foi então revisada e expandida para locais contaminados com outras substâncias com a publicação em 2000 da ASTM E2081 Chemical Release.

No Brasil, a metodologia RBCA é chamada de Ação Corretiva Baseada no Risco (ACBR) e foi normatizada pela ABNT por meio da Norma Brasileira (NBR) 16.209 (Associação Brasileira de Normas Técnicas, 2013a; Dias et al., 2001; Barros \& Carvalho, 2012).

0 estudo dos riscos associados a contaminantes no meio se tornou de extrema importância em casos onde os valores de intervenção estabelecidos pela legislação sejam impraticáveis. Assim, a avaliação estabelece concentrações mais flexíveis porém ainda protetivas à saúde humana e que são utilizadas como metas para a etapa de intervenção (Companhia Ambiental do Estado de São Paulo, 2006).

Algoritmos matemáticos foram desenvolvidos para auxiliar o estudo de caracterização e quantificação de riscos e concentrações máximas aceitáveis (CMA) (Regens et al., 2000). Um conjunto desses algoritmos formam ferramentas de avaliação de risco, que são amplamente utilizadas no desenvolvimento das etapas de avaliação de exposição, avaliação de toxicidade e caracterização e quantificação dos riscos à saúde humana (Spence \& Walden, 2013).

As ferramentas possibilitam ao usuário definir o modelo de exposição e as premissas específicas para cada área de estudo e apresentam resultados de forma padronizada e conveniente (American Society for Testing and Materials, 2015). Além disso, auxiliam nos cálculos de ingresso, de transporte e transformação de contaminantes e das concentrações máximas aceitáveis para cada contaminante de interesse e via de exposição (Spence \& Walden, 2013).

Alguns exemplos de ferramentas de avaliação de risco são: C-SOIL, CalTOX, RBCA Tool Kit, RISC (Risk Integrated Software for Clean-Ups), Risk-Net, MMSOILS. No Brasil, além dessas ferramentas, também são utilizadas as planilhas da Companhia Ambiental do Estado de São Paulo (CETESB), desenvolvidas pelo próprio órgão ambiental paulista. E em estudos de contaminações exclusivas de hidrocarbonetos derivados de petróleos, é empregado o modelo SCBR, desenvolvido pela UFSC e Petrobrás (Michels et al., 2004).

Segundo Joussef (2013), as planilhas da CETESB e o RISC estão entre os modelos mais utilizados para avaliação de risco.

Tendo em vista a variabilidade de ferramentas, que foram criadas por instituições e inicialmente focando em determinados grupos de contaminação, os algoritmos utilizados e as premissas aplicadas são diferentes entre elas. Alguns estudos em relação ao uso dessas ferramentas foram realizados por 
autores como: Correia et al. (2016), que utilizaram as planilhas da CETESB para quantificação de riscos associados a exposição de trabalhadores e residentes rurais a resíduos de rochas e polímeros, Nascimento (2015), que quantificou os riscos associados a metais encontrados no solo com as planilhas da CETESB e a ferramenta RBCA, Squissato (2012) propôs um estudo de avaliação de risco utilizando sistema de informações geográficas e as planilhas da CETESB. Cathcart (2014, 2017) realizou um estudo comparativo entre as planilhas da CETESB e os softwares RBCA Tool Kit e RISC4 e aplicou as planilhas para quantificação de risco associados a contaminação de chumbo e benzeno no meio físico, já Gonçalves \& Lena (2013) realizaram avaliações de risco utilizando as planilhas e a versão anterior do RISC4 para uma contaminação de arsênio.

Atualmente no Brasil não há uma exigência legal para o uso de uma ferramenta específica, tendo os avaliadores de risco uma gama ampla de possibilidades de modelos para empregarem nas quantificações em avaliações de risco mais detalhadas.

Neste contexto, o objetivo deste estudo foi determinar se há uma diferença objetiva no resultado de uma avaliação ao aplicar uma ferramenta em detrimento a outra. Foram avaliadas as Planilhas da CETESB e o software RISC5. Sendo as Planilhas da CETESB de aplicação obrigatória no estado de São Paulo e recomendada por outros órgãos ambientais estaduais, e o RISC5 um software comercial criado inicialmente para áreas contaminadas com hidrocarbonetos mas que atualmente abrange uma variedade maior de contaminantes e é utilizado amplamente tanto no Brasil como em outros países.

0 estudo também buscou identificar as possíveis especificidades no uso de cada instrumento ao longo do desenvolvimento da avaliação a fim de majorar o conhecimento sobre cada sistema. Para tanto, foram realizadas simulações de avaliações de risco aplicando dados reais de um terreno onde o aquífero está contaminado com compostos organoclorados.

\section{METODOLOGIA}

No desenvolvimento deste trabalho, as simulações de avaliação de risco foram realizadas conforme a metodologia ACBR normatizada pela Norma Brasileira (NBR) 16.209 (Associação Brasileira de Normas Técnicas, 2013a) e apresentada no Manual de Gerenciamento de Áreas Contaminadas (Companhia Ambiental do Estado de São Paulo \& Deutsche Gesellschaft für Technische Zusammenarbeit, 2001). Os dados utilizados para formulação do modelo conceitual foram baseados no histórico de trabalhos de investigação de passivos realizados por empresas de consultoria em uma área contaminada com organoclorados. Os potenciais cenários de exposição foram definidos a partir da análise de dados disponíveis sobre a potenciometria e sentido do fluxo de água subterrânea local, parâmetros físicos do solo (porosidade, umidade, densidades e granulometria), condutividade hidráulica e espacialidade das plumas de fase dissolvida. Por motivos de proteção e privacidade do proprietário do terreno, informações genéricas foram apresentadas sobre a localização espacial e a atividade desenvolvida.

As ferramentas escolhidas para as simulações de riscos à saúde humana na área de estudo foram as Planilhas da CETESB (Companhia Ambiental do Estado de São Paulo, 2013) e o software RISC5 (Spence \& Walden, 2013), que são amplamente utilizadas no Brasil para desenvolvimento de avaliações de risco no processo de gerenciamento de áreas contaminadas. As etapas executadas neste trabalho são apresentadas na Figura 2 e os principais passos descritos posteriormente. 


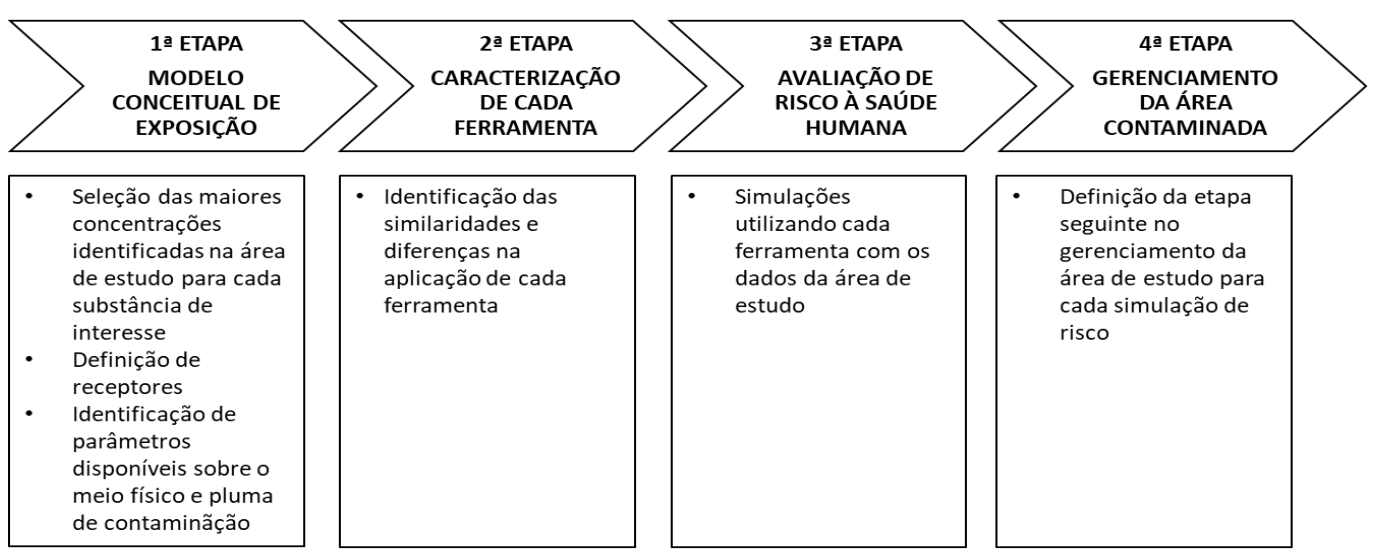

Figura 2. Fluxograma das etapas para o desenvolvimento do estudo comparativo das ferramentas de avaliação de risco

\section{Área de estudo}

A área de estudo refere-se ao terreno de uma empresa que comercializava produtos químicos e operou no local entre os anos 1974 e 2010. A propriedade possui cerca de $6.368 \mathrm{~m}^{2}$ e está localizada em área urbana com ocupação predominante residencial (Serviço Nacional de Aprendizagem Industrial, 2008; Eco Reg do Brasil, 2017). As atividades realizadas no local envolveram o armazenamento, o fracionamento e a distribuição de pequenas quantidades de produtos químicos diversos, bem como a lavagem de embalagens de produtos utilizando solventes (Akvoplan, 2009; Eco Reg do Brasil, 2011).

Os estudos de investigação de passivo ambiental foram realizados entre 2008 e 2017 e abrangeram a amostragem de solo, o monitoramento da qualidade da água subterrânea, bem como a instalação e a operação de um sistema de bombeamento para tratamento da água. Os trabalhos de investigação confirmaram que o hot spot das maiores concentrações de percloroetileno e tricloroetileno localiza-se onde as embalagens vazias utilizadas na atividade eram lavadas com solventes. 0 monitoramento ao longo da operação do sistema de tratamento também indicou uma redução das concentrações de PCE e TCE, porém, os compostos quantificados permaneceram acima dos valores de investigação de Brasil (2009).

A caracterização da área de estudo e da contaminação existente foi realizada com base nas informações apresentadas nos relatórios de investigações ambientais a fim de se formular o modelo conceitual da área. Os parâmetros referentes a dimensão da pluma dos compostos de interesse e do meio contaminado foram utilizados na estimativa de exposição a vapores de substâncias tóxicas pelos receptores. Os dados obtidos foram empregados nos modelos matemáticos que representam o transporte de vapores pela zona saturada e zona vadosa até o contato indireto com o receptor.

\section{Ferramentas de avaliação de risco}

Planilhas da CETESB

As planilhas da CETESB são um conjunto de algoritmos configurados por meio do programa Microsoft Excel ${ }^{\circledR}$ pelo órgão ambiental paulista, a CETESB. Elas são a ferramenta obrigatória no desenvolvimento de avaliações dos riscos carcinogênicos e não carcinogênicos em áreas contaminadas naquele estado. Além disso, é utilizada para a definição de concentrações aceitáveis para a área, auxiliando a etapa de intervenção e a tomada de decisão sobre a área em estudo (Companhia Ambiental do Estado de São Paulo, 2017).

Segundo Maximiano (2011), as planilhas da CETESB são de fácil utilização e consolidam e unificam dados referentes às substâncias químicas e aos parâmetros de exposição. Está ferramenta é aceita amplamente por órgãos de controle ambiental de outros estados do país (Sanberg et al., 2015).

RISC5

O software comercial Risk Integrated Software for Clean-Ups é usualmente conhecido apenas pela sua sigla RISC5, sendo que o número se refere a sua versão. Esse algoritmo foi desenvolvido pela 
British Petroleum, em parceria com Spence Environmental Engineering, para quantificação dos riscos à saúde humana e ecológicos associados a áreas contaminadas.

Também é utilizado para a definição de metas de remediação e modelagem do transporte de substâncias químicas de interesse. Sua primeira versão foi publicada em janeiro de 1994 e a quinta, e mais recente versão, foi divulgada em dezembro de 2010 (Spence \& Walden, 2013).

\section{Correspondência e identificação de atributos, dados padrão e algoritmos das ferramentas}

Esta etapa do trabalho buscou sintetizar as variantes identificadas durante a aplicação das ferramentas para o desenvolvimento de uma avaliação de risco à saúde humana. Para tanto as seguintes informações foram identificadas por meio da interação com as ferramentas, pesquisa nos materiais de apoio ao usuário e informações disponibilizadas pelos desenvolvedores:

- $\quad$ Ano de desenvolvimento/última atualização;

- Custo;

- $\quad$ Receptores disponíveis;

- Vias de exposição disponíveis;

- $\quad$ Disponibilidade de alteração de parâmetros;

- $\quad$ Bancos de dados

- Algoritmos e metodologias empregados nos cenários de inalação de vapores

Ainda, foi realizado um levantamento de todos os parâmetros necessários para a avaliação de riscos envolvendo a inalação de vapores por residentes e trabalhadores de obras on site. Cada ferramenta utilizou uma nomenclatura para definir um mesmo parâmetro, portanto, também foi necessária a realização de uma correspondência entre eles.

\section{Simulações de avaliação de risco}

A etapa de quantificação de riscos utilizando as ferramentas envolveu um conjunto de simulações de avaliações de risco utilizando ambas as ferramentas, planilhas da CETESB e RISC5. A avaliação de risco simulada foi baseada na contaminação existente na área de estudo e cenários de exposição via inalação de vapores. Dessa maneira, as características específicas do meio físico e da contaminação, identificadas e definidas na primeira etapa deste trabalho, foram aplicadas em ambas as ferramentas a fim de se obter resultados referentes a um mesmo caso de contaminação.

As simulações executadas buscaram investigar o uso mais habitual das Planilhas da CETESB e do software RISC5 por consultores. Neste caso, foram introduzidos apenas dados relacionados a contaminação e meio físico representantes da área de estudo. Quaisquer outros dados, exposicionais, características de compostos etc., não foram alterados.

Os resultados disponibilizados pelas Planilhas da CETESB e pelo software RISC5 foram comparados para avaliar uma possível influência no resultado final da avaliação de risco, e consequentemente para o gerenciamento da área contaminada, ao se optar por uma ou outra ferramenta.

Foram estudados os resultados das concentrações no ponto de exposição, riscos e concentrações máximas aceitáveis quantificados e as possíveis metas de intervenção. Como metas de intervenção que fundamentariam os projetos de intervenção e gerenciamento de riscos foram consideradas as CMA mais restritivas.

\section{RESULTADOS E DISCUSSÃO}

Para uma melhor aplicação e escolha de ferramentas de apoio à avaliação de risco à saúde humana no âmbito do gerenciamento de áreas contaminadas é importante conhecer os seus atributos e características. Os resultados mais importantes da etapa de identificação das similaridades e diferenças durante o uso das Planilhas da CETESB e software RISC5 são discutidos a seguir, e as características gerais foram sintetizadas no Quadro 1. 
Quadro 1. Síntese das principais diferenças entre as ferramentas para avaliação de risco à saúde humana.

\begin{tabular}{|c|c|c|}
\hline Atributo & Planilhas da CETESB & RISC5 \\
\hline Atualização & 2013 & 2011 \\
\hline Licença para uso & gratuita & $\begin{array}{l}\$ 875 \text {, equivalente a } \mathrm{R} \$ 3.565 \text { pela } \\
\text { cotação do Banco Central do Brasil em } \\
10 / 01 / 2020 \text {. }\end{array}$ \\
\hline Manual & Não possui & Possui guia do usuário e tutorial. \\
\hline Banco de dados & $\begin{array}{l}\text { Banco de dados atualizado em } 2012 \text { e } \\
\text { conta com } 755 \text { substâncias. } \\
\text { Encontra-se atualizado conforme RSL } \\
\text { publicada em } 2017 \text { pela U.S.EPA }\end{array}$ & $\begin{array}{l}\text { Banco de dados atualizado em } 2011 \text { e } \\
\text { conta coma } 128 \text { substâncias. } \\
\text { Encontra-se desatualizado conforme } \\
\text { RSL publicada em } 2017 \text { pela U.S.EPA }\end{array}$ \\
\hline Receptores padrão & Limitados & $\begin{array}{l}\text { Receptores aditivos e personalizáveis } \\
\text { (ilimitados) }\end{array}$ \\
\hline Entrada de dados & $\begin{array}{l}\text { Limitação de inserção de dados } \\
\text { toxicológicos, exposicionais, escolha de } \\
\text { modelo matemático }\end{array}$ & Flexível \\
\hline $\begin{array}{l}\text { Apresentação de } \\
\text { resultados }\end{array}$ & $\begin{array}{l}\text { Diretamente no arquivo do Microsoft } \\
\qquad \text { Excel }^{\circledR} \\
\text { Instantaneamente com a introdução/ } \\
\text { modificação de dados }\end{array}$ & $\begin{array}{l}\text { Os resultados são apresentados a parte } \\
\text { no Microsoft Excel } \\
\text { Caso haja modificação dos dados de } \\
\text { entrada a atualização dos resultados } \\
\text { deve ser solicitada através de comando } \\
\text { no software RISC5 } \\
\text { CMA são apresentadas apenas para os } \\
\text { cenários críticos (maior risco) }\end{array}$ \\
\hline Cenários de exposição & $\begin{array}{l}\text { Não possuem cenários de exposição } \\
\text { acidental ou eventuais, cenários } \\
\text { disponíveis são limitados }\end{array}$ & $\begin{array}{l}\text { Possibilidade de personalização de } \\
\text { cenários de exposição acidental ou } \\
\text { eventual (transeunte) }\end{array}$ \\
\hline \multirow{2}{*}{ Modelagem } & $\begin{array}{l}\text { Quantificação de riscos cumulativos por } \\
\text { via de exposição e SQI }\end{array}$ & $\begin{array}{l}\text { Quantificação de riscos cumulativos por } \\
\text { composto, via de exposição e total }\end{array}$ \\
\hline & $\begin{array}{l}\text { CMA quantificadas por substância e via } \\
\text { de exposição }\end{array}$ & $\begin{array}{l}\text { CMA quantificadas cumulativas por } \\
\text { cenário de exposição ou total }\end{array}$ \\
\hline
\end{tabular}

\section{Metodologia e premissas empregadas pelas ferramentas}

- Riscos e CMA: Este estudo permitiu verificar que as metodologias para quantificação de riscos carcinogênicos e não carcinogênicos (quociente de perigo) utilizadas por ambas as ferramentas seguem de maneira geral as diretrizes estabelecidas pela United States Environmental Protection Agency (1989) e American Society for Testing and Materials (2012, 2015), bem como sua versão brasileira, ACBR, normatizada na NBR 16.209 (Associação Brasileira de Normas Técnicas, 2013a). Ambas calculam riscos individuais e acumulados, entretanto, não consideram para o risco não carcinogênico total apenas as substâncias com mecanismos de ação similares. Além disso, como detalhado a frente, as Planilhas da CETESB não permitem determinar concentrações máximas aceitáveis que quando consideradas em conjunto resultam em riscos totais aceitáveis.

Através da avaliação da aplicação das Planilhas da CETESB, verificou-se que esta ferramenta permite a quantificação de concentrações máximas aceitáveis (CMA) apenas para um determinado caminho de exposição e para um composto químico por vez. Ou seja, é estimada uma CMA, para cada composto químico e para cada via de exposição individualmente. 0 usuário tem acesso a cada uma delas, e pode fazer análises críticas considerando premissas especificas do modelo conceitual daquela área exclusivamente, por exemplo separar a avaliação de cenários hipotéticos.

Entretanto, a ferramenta não quantifica as CMA considerando o risco total (cumulativo) de várias substâncias interagindo com um mesmo receptor através de uma via de exposição, ou o risco total (cumulativo) de uma mesma substância interagindo com o receptor através de várias vias de exposição. Assim, as concentrações estimadas como aceitáveis pelas Planilhas da CETESB, quando consideradas em conjunto em um plano de gerenciamento de risco ainda podem indicar risco cumulativo acima do aceitável.

Tal constatação demonstra uma incongruência nos procedimentos das normativa jurídica mais atualizadas em vigor no país, como a Decisão Diretoria no 38/2017 no estado de São Paulo (Companhia Ambiental do Estado de São Paulo, 2017) e a Instrução Normativa no 74/2018 em Santa Catarina 
(Instituto do Meio Ambiente, 2018). Nas referidas normativas, os órgãos ambientais solicitam que 1) seja utilizada como regra a ferramenta "Planilhas da CETESB" para avaliação dos riscos e quantificação de CMA 2) seja quantificado o risco total (cumulativo), este que será o indicador principal para a tomada de decisão quanto a necessidade de adoção de medidas de intervenção e 3) o risco não carcinogênico cumulativo deve considerar apenas riscos individuais de substâncias com mecanismos semelhantes de ação .

Porém, como apresentado anteriormente, as Planilhas da CETESB determinam apenas CMA relacionadas a riscos específicos para cada substância química de interesse (SQI) e cada caminho de exposição. Dessa forma, tem-se que o processo de reabilitação de áreas contaminadas não é planejado com base em concentrações que em conjuntam resultam em uma exposição com risco total aceitável, podendo a população estar sujeita a riscos de desenvolver efeitos adversos quando exposta a uma mistura de contaminantes presentes no meio.

Constatou-se, em contrapartida, que o software RISC5 possibilita a quantificação de concentrações máximas aceitáveis ponderadas com base no risco total da exposição a uma mistura de SQI. Neste caso, a soma dos riscos associados a cada CMA também serão aceitáveis. Quanto a avaliação individual de CMA para cada cenário de exposição, o software RISC5 apresenta ao usuário apenas o resultado referente ao cenário mais restritiva, sem disponibilizar concentrações específicas por via, receptor e tipo de risco associado (carcinogênico ou não carcinogênico). Essa disponibilização limitada de resultados compromete a análise crítica e personalizada pelo usuário para a área em estudo, o que pode interferir nas fundamentações para as etapas seguintes de intervenção e gerenciamento de riscos.

- Exposição em ambiente aberto: A área de exposição via inalação em ambiente aberto foi considerada de maneira padrão nas planilhas da CETESB como o tamanho da pluma de contaminação. Já o RISC5 utilizou a metodologia chamada "box" (caixa), que considerou o receptor dentro de uma caixa, cuja largura, comprimento e altura são definidos pelo usuário. Apesar desta disponibilidade de personalização de dados, o algoritmo considera que a carga de contaminantes de toda a pluma contribui no espaço delimitado, a caixa de exposição. Se o usuário considerar áreas de exposição menores do que a pluma, a concentração no ambiente externo e consequentemente os riscos podem ser superestimados.

- Inalação de vapores: Durante o desenvolvimento deste trabalho, foi constatado que nenhuma das ferramentas aplica a nova metodologia da United States Environmental Protection Agency (2009) para quantificação de riscos associados a inalação de vapores. 0 método mais recente considera a utilização de uma concentração de referência (RfC) e um risco unitário de inalação (IUR) como dados toxicológicos no lugar da dose de referência (RfD) e fator de carcinogenicidade (SF). Dessa forma, o peso corpóreo (BW) e a taxa de inalação (IR), que são parâmetros específicos do receptor, não são empregados no novo método. Assim, a dose de ingresso depende fortemente dos tempos de exposição e não mais da quantidade de contaminante que entra no corpo, estimada pela taxa de inalação, peso corporal juntamente com a concentração no ar.

Neste estudo foi constatado que ambas as ferramentas utilizaram os novos parâmetros toxicológicos, RfC e IUR, para calcular a RfD e o SF, respectivamente, como uma tentativa de aplicar a nova metodologia. Entretanto, tal manobra aplicou valores diferentes para um mesmo parâmetro exposicional no algoritmo geral de cálculo de risco, evidenciando que não foi aplicada a nova metodologia. Ademais, a conversão realizada através da aplicação do peso corporal e da taxa de inalação utilizou apenas o dado padrão de um receptor adulto, não adaptando os valores para receptores crianças. 0 uso da abordagem antiga da U.S.EPA em cenários com receptores crianças, sem adequação correta a nova metodologia, contribui para um resultado mais conservador na quantificação do ingresso de receptores crianças. Tal resultado também foi verificado na comparação de modelos realizada por Han et al. (2016).

- Intrusão de vapores em ambientes fechados: 0 software RISC5 disponibilizou durante as simulações realizadas a possibilidade de utilização de modelagem de vapores considerando processos advectivos de transporte. Contudo, optou-se pela realização de uma abordagem simplificada e similar àquela empregada pelas planilhas da CETESB na qual a quantificação das concentrações de contaminantes no ar em ambiente fechado consideram apenas o transporte difusivo. Dessa forma ambas as ferramentas basearam seus algoritmos de transporte e intrusão de vapores no modelo de Johnson \& Ettinger (1991). 0 modelo matemático empregado portanto é uma simplificação do modelo de Johnson \& Ettinger (1991), pois não considera o transporte advectivo da metodologia original. Segundo Gouvêa Júnior (2011), o fluxo advectivo de entrada de vapores em edificações ocorre principalmente em casas com porões devido a vários fatores como: mudanças barométricas, correntes 
térmicas, despressurização de ambientes. Deste modo, a premissa adotada pelas Planilhas da CETESB está condizente com a realidade das casas brasileiras, que, em sua maioria, não possuem porões ou áreas fechadas no subsolo.

- Carcinogênicos mutagênicos: Verificou-se que nenhuma das ferramentas aplicadas neste trabalho considerou o fator de ajuste por idade - Age Dependent Adjustment Factor (ADAF). Segundo Toledo (2016), esta abordagem ainda é recente, e resulta em uma avaliação mais conservadora. 0 ADAF está relacionado ao efeito de mutagenicidade de um com composto químico (United States Environmental Protection Agency, 1989). Os cânceres relacionados a este efeito são mais suscetíveis em crianças. A U.S.EPA indica portanto a aplicação do ADAF para a quantificação de riscos envolvendo crianças como receptores, visto que os dados toxicológicos disponíveis são baseados em estudos com animais em estágio maduro de desenvolvimento.

\section{Receptores}

São disponibilizados como receptores padrão, cujos dados exposicionais já estão predefinidos nas ferramentas, quatro opções no software RISC5 e seis nas Planilhas da CETESB. Ambos consideram como receptores padrão os residentes crianças e adultos, trabalhadores de obras e comerciais. Além desses, a ferramenta da CETESB incluí receptores residentes de áreas rurais e o RISC5 um receptor recreacional. Notou-se que as vias consideradas recreacionais para receptores residentes nas Planilhas da CETESB não estão disponíveis na versão atual (Companhia Ambiental do Estado de São Paulo, 2013).

0 software RISC5 ainda permite a adição manual em seu banco de dados de receptores personalizados conforme a necessidade do avaliador de risco. Tal propriedade torna a ferramenta ilimitada em termos de definição de receptores. Entretanto, notou-se que em cada simulação da avaliação de risco pelo RISC5 foi possível selecionar no máximo dois receptores.

A principal particularidade constatada no software RISC5 em relação aos receptores foi a possiblidade de simulação de um receptor "aditivo". Na quantificação dos riscos do receptor aditivo, o algoritmo que expressa o ingresso de contaminantes considera o tempo de exposição durante a infância e a fase adulta, complementarmente. 0 receptor, por conseguinte, representaria uma pessoa que permanece no local avaliado desde a infância até a fase adulta. Consequentemente, os riscos à saúde humana quantificados seriam mais representativos da realidade de um morador da área a longo prazo.

\section{Cenários de Exposição}

Ambas as ferramentas analisadas têm limitações quanto à escolha e aplicação de cenários de exposição. Com o software RISC5, não foi possível realizar simulações para receptores on e off site simultaneamente, além da avaliação de apenas dois receptores por simulação, conforme já mencionado. Em compensação, as planilhas da CETESB não contam com cenários mais específicos e reais como os considerados pelo RISC5. Exemplos desses cenários são: os receptores aditivos, trabalhadores de obras fora do site, exposição via irrigação e ingestão de vegetais irrigados com água contaminada.

\section{Banco de Dados}

- Características dos Compostos Químicos: 0 banco de dados de valores toxicológicos e físicoquímicos das planilhas da CETESB foi atualizado em 2013 quando houve também a inclusão de informações de novas substâncias inseridas na ferramenta e encontram-se atualizados com dados mais recentes do IRIS (United States Environmental Protection Agency, 2017a).

Em relação aos dados utilizados pelo RISC5, averiguou-se que a maioria dos parâmetros físicoquímicos no RISC5 provém de referências da década de 90. Os fatores toxicológicos também foram baseados nos níveis RSL da U.S.EPA, porém, na lista divulgada em 2010. Para o composto TCE constatou-se a ausência de valor toxicológico para efeitos não carcinogênicos (RfC) devido a remoção desses dados da lista RSL em 2008. Portanto, constatou-se que apesar da atualização em 2011, o RISC5 ainda emprega dados toxicológicos desatualizados, tanto para o PCE como TCE, e que impossibilitaram a quantificação de quocientes de perigo (HQ) para os cenários de inalação avaliados.

Parâmetros Exposicionais: As principais disparidades observadas entre os valores de exposição utilizados pelas ferramentas foram a taxa de inalação e tempos de exposição. Identificou-se que os tempos considerados pelas planilhas da CETESB para a exposição via inalação em ambiente 
aberto e fechado são complementares para os receptores residenciais, totalizando as 24 horas de um dia. A ferramenta considerou que a exposição, tanto de crianças como adultos, foi de 16 horas em ambiente fechado e 8 horas em ambientes abertos. Já o software RISC5 considerou 24 horas de exposição nos dois cenários. Neste caso, o risco cumulativo das vias de exposição seria super estimado e não representativo da realidade.

Em relação ao tempo de exposição de trabalhadores de obras, as duas ferramentas consideraram 8 horas de exposição em ambiente aberto referente a uma jornada de trabalho. A exposição em ambiente fechado não foi considerada no RISC5 pois a frequência de exposição padrão foi nula.

Além disso, a duração da exposição de trabalhadores de obras foi considerada, em ambas as ferramentas, como de 2 anos. Todavia, essa duração também pode ser variável, segundo estudo realizado por Coutinho et al. (2012), o tempo de execução de uma obra varia com a área a ser construída, o custo orçado, a capacidade técnica operacional, a tipologia do serviço e a estação do ano.

Ainda que, conforme Maximiano (2011) as Planilhas da CETESB considerem cenários de exposição adaptados à realidade brasileira, os dados apresentados na versão atualizada em 2013, foram baseados principalmente em referências publicadas pela U.S.EPA. Observa-se ainda que os valores exposicionais não atenderam recomendações mais atuais e realísticas do mesmo órgão (United States Environmental Protection Agency, 2011) utilizada como referência nos estudos de risco desenvolvidos por Toledo (2016).

Couto (2006) verificou que fatores exposicionais apresentados por fontes internacionais não condizem com a realidade brasileira. Como os fatores exposicionais dependem das incertezas associadas aos métodos de amostragem de dados, e da variabilidade espacial, temporal e entre indivíduos, o autor ainda destacou que existem diferenças significativas entre os fatores exposicionais mesmo entre regiões do país, e, por conseguinte, recomenda que as avaliações de riscos adotem parâmetros específicos para cada estudo. Como discutido a seguir neste trabalho, dentre as duas ferramentas avaliadas neste estudo, apenas o software RISC5 permite ao usuário a personalização recomendada por Couto (2006).

\section{Entrada de dados}

A comparação da aplicação das ferramentas empregadas neste trabalho identificou como diferença mais sensível a liberdade de modificação e inserção de dados para quantificação dos riscos e CMA. No desenvolvimento da avaliação de risco com o software RISC5 foi possível modificar livremente os valores dos parâmetros necessários para a quantificação dos riscos e CMA, como limites aceitáveis de risco, parâmetros de toxicidade, franja capilar entre outros. Em contrapartida, a ferramenta da CETESB só possibilitou a modificação de algumas informações referentes à contaminação e ao meio físico.

Outro ponto verificado na utilização das planilhas da CETESB foi referente a divisão dos parâmetros necessários nos modelos matemáticos por via de exposição. Os parâmetros utilizados em mais de uma via de exposição foram requeridos apenas uma vez. Neste estudo, foi o caso dos parâmetros fração de carbono orgânico e densidade do solo apresentados junto à seção de inalação de vapores, mas que também foram empregados no modelo matemático de transporte de contaminantes em zona saturada, que pode incluir outras vias de exposição off site. Caso a inalação de vapores não fosse considerada, tais parâmetros poderiam não ter sido especificados para a área avaliada.

A rigidez na inserção de dados e detalhamento do modelo conceitual de exposição de uma área de estudo nas Planilhas da CETESB, se verifica como uma medida de segurança para a avaliação de estudos por parte dos órgãos ambientais. Entretanto, impossibilita e prejudica a personalização de cenários de exposição e personalização de modelos conceituais de exposição, que tendem a ser mais complexos com o avanço das investigações.

\section{Riscos à Saúde Humana}

Os riscos carcinogênicos quantificados nas simulações realizadas foram considerados inaceitáveis quando acima de $10^{-5}$, e os quocientes de perigo (riscos não carcinogênicos) quando maiores que 1. 0 limite utilizado neste estudo representa um caso adicional de câncer em uma população de 100.000 habitantes expostos. Em relação ao risco não carcinogênicos, os cenários avaliados como inaceitáveis referem-se àqueles cujo ingresso da substância de interesse foram maiores que a concentração de referência (RfC). 
Esses limites também foram utilizados em avaliações de risco realizadas por Michels et al. (2004) e Gonçalves \& Lena (2013) referente a áreas contaminadas do estado de São Paulo e Minas Gerais, respectivamente. De modo diferente, nos estudos realizados por Chang et al. (2004), Fan et al. (2010) e Han et al. (2016) em áreas localizadas na Ásia, o limite adotado para risco carcinogênico foi de $10^{-6}$. Observou-se, portanto, que a abordagem para efeitos carcinogênicos tem sido mais conservadora em outros países, seguindo o limite mais crítico de risco adotado pela United States Environmental Protection Agency (2017b).

\section{Inalação em ambiente aberto}

As simulações de avaliação de risco para exposição de PCE e TCE via inalação em ambiente aberto utilizando as planilhas da CETESB e o software RISC5 derivaram riscos aceitáveis para todos os receptores investigados (crianças, adultos e trabalhadores de obras). Os resultados numéricos das simulações para a exposição via inalação em ambiente aberto são apresentados nas Tabela 1 a Tabela 4.

De maneira geral, os riscos à saúde humana relacionados a contaminação caracterizada na área de estudo foram maiores na aplicação da ferramenta planilhas da CETESB. Neste caso, a substância crítica para ambos os efeitos considerados (carcinogênico e não carcinogênico) foi o tricloroetileno (TCE). Em contrapartida, a substância crítica para a avaliação utilizando o RISC5 foi o percloroetileno (PCE).

Os riscos carcinogênicos quantificados para o composto PCE (Tabela 1) variaram em duas ordens de grandeza, entre 8,63 10-10 e 1,56 10-8 pelas planilhas da CETESB. Os riscos quantificados pelo RISC5 variaram em uma ordem apenas, entre 5,41 10-11 e 7,04 10-10. Em relação ao TCE (Tabela 2) os riscos quantificados pelas planilhas da CETESB variaram em apenas uma ordem entre $1,2310^{-8}$ e 2,23 10 O software RISC5 quantificou valores menores, variando entre 1,44 10-11 e 1,88 10-10.

Tabela 1. Riscos carcinogênicos associados à inalação em ambiente aberto de PCE

\begin{tabular}{|c|c|c|}
\hline Receptores & Planilhas da CETESB & RISC5 \\
\hline Adulto on site & $1,5610^{-08}$ & $2,9710^{-10}$ \\
\hline Criança on site & $9,4710^{-09}$ & $7,0410^{-10}$ \\
\hline Trabalhador de obras & $8,6310^{-10}$ & $5,4110^{-11}$ \\
\hline
\end{tabular}

Tabela 2. Riscos carcinogênicos associados à inalação em ambiente aberto de TCE

\begin{tabular}{|c|c|c|}
\hline Receptores & $\begin{array}{l}\text { Planilhas da } \\
\text { CETESB }\end{array}$ & RISC5 \\
\hline Adulto on site & $2,2310^{-07}$ & $7,9310^{-11}$ \\
\hline Criança on site & $1,3510^{-07}$ & $1,8810^{-10}$ \\
\hline Trabalhador de obras & $1,2310^{-08}$ & $1,4410^{-11}$ \\
\hline
\end{tabular}

Os riscos não carcinogênicos associados ao composto PCE (Tabela 3) foram considerados teoricamente nulos em todos os cenários avaliados com exceção do receptor criança na simulação realizada com as planilhas da CETESB $(0,01)$. Como já discutido anteriormente, o quociente de perigo para o composto TCE (Tabela 4) não pode ser quantificado utilizando o software RISC5. Os valores quantificados pelas planilhas da CETESB variaram entre 0,05 e 0,20 permanecendo dentro do limite aceito.

Tabela 3. Riscos não carcinogênicos associados à inalação em ambiente aberto de PCE

\begin{tabular}{|c|c|c|}
\hline Receptores & $\begin{array}{l}\text { Planilhas da } \\
\text { CETESB }\end{array}$ & RISC5 \\
\hline Adulto on site & 0,00 & 0,00 \\
\hline Criança on site & 0,01 & 0,00 \\
\hline Trabalhador de obras & 0,00 & 0,00 \\
\hline
\end{tabular}


Tabela 4. Riscos não carcinogênicos associados à inalação em ambiente aberto de TCE

\begin{tabular}{c|c|c}
\hline \multicolumn{1}{c}{ Receptores } & $\begin{array}{c}\text { Planilhas da } \\
\text { CETESB }\end{array}$ & RISC5 \\
\hline Adulto on site & 0,07 & NC \\
\hline Criança on site & 0,20 & NC \\
\hline Trabalhador de obras & 0,05 & NC \\
\hline
\end{tabular}

NC: Não calculado.

Diante dos resultados obtidos, a rota de exposição por inalação em ambiente aberto de vapores de PCE e TCE provenientes da pluma de água contaminada foi considerada não significativa.

0 residente adulto foi o receptor mais sensível para os efeitos carcinogênicos tanto da contaminação por PCE como TCE nas simulações realizadas com as planilhas da CETESB. Em comparação, a simulação com o software RISC5 resultou em maiores valores de riscos para o receptor criança. Esses resultados estão atrelados a parâmetros de exposição que dependem do receptor investigado.

O receptor mais crítico em relação aos efeitos não carcinogênicos foram as crianças, tanto para a contaminação de PCE como TCE utilizando as planilhas da CETESB. No caso do RISC5, como já comentado, os resultados para PCE foram virtualmente nulos, e para TCE não foram calculados por ausência de dados toxicológicos.

Os resultados entre as ferramentas variaram de uma a três casas decimais. As discrepâncias entre os resultados podem ser explicadas pela variação entre os dados exposicionais empregados por cada ferramenta, como por exemplo as taxas de inalação e tempo de exposição, bem como pelos modelos matemáticos empregados na quantificação das concentrações no ponto de exposição. Esses resultados também foram encontrados por Han et al. (2016) em estudo que comparou os resultados de outras duas ferramentas de avaliação de risco. Esses autores concluíram que os parâmetros de exposição influenciaram nas diferenças dos riscos calculados pelas ferramentas.

Nesta via de exposição, inalação em ambiente aberto, os algoritmos empregados foram variações da metodologia publicada por Johnson \& Ettinger (1991), e no caso do software RISC5 incluiu ainda o chamado método da caixa. As concentrações no ponto de exposição em ambiente aberto variaram em duas ordens de grandeza entre as ferramentas.

A identificação dos contaminantes críticos, ou seja, as substâncias responsáveis pelos maiores riscos, é importante pois esta será uma das principais informações utilizadas na etapa de intervenção, sendo o principal alvo das ações remediadoras. A partir do estudo realizado, constatou-se que as ferramentas indicaram diferentes substâncias críticas. Os maiores riscos nas simulações com as planilhas da CETESB foram verificados para o TCE. Em oposição, o cenário crítico com o uso do RISC5 pode ser observado para o PCE. Dessa maneira, verificou-se que os parâmetros específicos das substâncias de interesse influenciaram também o resultado final das avaliações realizadas.

Inalação em ambiente fechado

Dentre as simulações de risco realizadas considerando a via de exposição inalação de vapores em ambiente fechado, apenas as planilhas da CETESB quantificaram riscos inaceitáveis. Esses cenários críticos envolvem a exposição indireta ao TCE por crianças, adultos e trabalhadores de obras que estão sujeitos a apresentarem efeitos adversos carcinogênicos e não carcinogênicos. Os resultados numéricos das simulações para a exposição via inalação em ambiente aberto são apresentados nas Tabela 5 a Tabela 8 .

De maneira geral, os riscos à saúde humana relacionados a contaminação caracterizada na área de estudo foram maiores na aplicação da ferramenta planilhas da CETESB, com exceção dos riscos carcinogênicos associados ao PCE. A substância crítica nas planilhas para ambos os efeitos considerados (carcinogênico e não carcinogênico) foi o tricloroetileno (TCE). Em contrapartida, a substância crítica para a avaliação utilizando o RISC5 foi o percloroetileno (PCE).

Ambas as ferramentas utilizaram como base de seus algoritmos o modelo consagrado de Johnson \& Ettinger (1991) para calcular o transporte através da franja capilar e zona vadosa e a intrusão de vapores pela fundação das construções. As concentrações no ponto de exposição diferiram em uma ordem de grandeza entre as planilhas da CETESB e o RISC5.

Os riscos carcinogênicos quantificados para o composto PCE (Tabela 5) pelas planilhas da CETESB variaram em duas ordens de grandeza, entre 4,09 10-8 e 1,36 10-6. A avaliação realizada com o RISC5 indicou riscos maiores, que variaram em uma ordem, entre 9,92 10 $10^{-7}$ e 4,02 10-6. 
Em relação ao TCE (Tabela 6), os riscos carcinogênicos quantificados pelas planilhas da CETESB também variaram duas ordens entre 1,88 $10^{-5}$ e 5,59 $10^{-7}$ e foram maiores que os riscos estimados pelo software RISC5 que variaram entre 1,44 10-11 e 1,88 10-10. As planilhas ainda identificaram os quocientes de perigo para o TCE inaceitáveis para exposição de crianças e adultos.

Tabela 5. Riscos carcinogênicos associados à inalação em ambiente fechado de PCE

\begin{tabular}{|c|c|c|}
\hline Receptores & Planilhas da CETESB & RISC5 \\
\hline Adulto on site & $1,3610^{-6}$ & $4,0210^{-6}$ \\
\hline Criança on site & $8,3110^{-7}$ & $9,9210^{-7}$ \\
\hline Trabalhador de obras & $4,0910^{-8}$ & NC \\
\hline
\end{tabular}

Tabela 6. Riscos carcinogênicos associados à inalação em ambiente fechado de TCE

\begin{tabular}{|c|c|c|}
\hline Receptores & Planilhas da CETESB & RISC5 \\
\hline Adulto on site & $1,8810^{-5}$ & $1,0510^{-6}$ \\
\hline Criança on site & $1,1510^{-5}$ & $2,5910^{-7}$ \\
\hline Trabalhador de obras & $5,5910^{-7}$ & NC \\
\hline
\end{tabular}

Os riscos não carcinogênicos associados ao PCE (Tabela 7) foram todos quantificados abaixo do limite aceitável por ambas as ferramentas. Sendo que as planilhas da CETESB indicaram cenários mais críticos, variando de 0,14 a 0,96. O RISC5 indicou quociente de perigo de 0,01 para os dois receptores avaliados. Nota-se que o RISC5 também não indicou valores associados a exposição em ambiente fechado para trabalhadores de obras pois considerou o tempo de exposição como nulo.

Em relação ao TCE (Tabela 8), conforme já mencionado, o software RISC5 não quantificou riscos relacionados a exposição pela ausência de dados toxicológicos.

A simulação realizada com as planilhas da CETESB indicou quocientes de perigo acima do aceitável para os três receptores avaliados (adulto, criança e trabalhador de obras). Neste caso o cenário mais crítico está relacionado à exposição indireta de crianças a vapores de TCE.

Tabela 7. Riscos não carcinogênicos (quocientes de perigo) associados à inalação em ambiente fechado de PCE

\begin{tabular}{|c|c|c|}
\hline Receptores & Planilhas da CETESB & RISC5 \\
\hline Adulto on site & 0,31 & 0,01 \\
\hline Criança on site & 0,96 & 0,01 \\
\hline Trabalhador de obras & 0,14 & $\mathrm{NC}$ \\
\hline
\end{tabular}

NC: Não calculado

Tabela 8. Riscos não carcinogênicos (quocientes de perigo) associados à inalação em ambiente fechado de TCE

\begin{tabular}{|c|c|c|}
\hline Receptores & Planilhas da CETESB & RISC5 \\
\hline Adulto on site & 5,51 & NC \\
\hline Criança on site & 16,78 & NC \\
\hline Trabalhador de obras & 2,45 & $\mathrm{NC}$ \\
\hline
\end{tabular}

NC: Não calculado

Diante dos resultados obtidos, a rota de exposição por inalação em ambiente fechado de vapores de PCE e TCE provenientes da pluma de água subterrânea contaminada foi considerada como significativa.

0 residente adulto on site foi o receptor mais sensível para os efeitos carcinogênicos para a contaminação por PCE e TCE nas simulações realizadas com as planilhas da CETESB e com o software RISC5. 
Os riscos não carcinogênicos (quocientes de perigo) quantificados pelas planilhas da CETESB indicaram a criança on site como receptor crítico para o PCE e o TCE. Esses resultados estão de acordo com os obtidos por Gouvêa Júnior (2011) na comparação feita entre os riscos para a via inalação quantificados pelas planilhas da CETESB, U.S.EPA e BioVapor, visto que os resultados também foram mais conservadores com a aplicação da ferramenta nacional. A avaliação de risco não carcinogênico da inalação em ambiente fechado com o RISC5 indicou quocientes de perigo similares para ambos os receptores residenciais. Nota-se que para TCE não foram calculados os riscos por ausência de dados toxicológicos.

Nesta via de exposição, inalação em ambiente fechado, os algoritmos empregados foram variações da metodologia publicada por Johnson \& Ettinger (1991). Para fins de comparação de resultados, no uso do software RISC5, optou-se pela seleção do algoritmo que abrange apenas o transporte de contaminantes por difusão, visto que nas Planilhas da CETESB somente essa modelagem é possível. As concentrações no ponto de exposição em ambiente fechado variaram em apenas uma ordem de grandeza entre as ferramentas.

Os resultados de risco entre as ferramentas variaram de uma a duas casas decimais. As discrepâncias entre os resultados podem ser explicadas pela variação entre os dados exposicionais empregados por cada ferramenta, como por exemplo as taxas de inalação e tempo de exposição, bem como pelos modelos matemáticos empregados na quantificação das concentrações no ponto de exposição. Como já apresentado anteriormente, as diferenças nos dados exposicionais considerados pelas ferramentas também foram consideradas como influenciadores dos resultados das avaliações de risco desenvolvidas por Han et al. (2016).

Como já mencionado, a identificação dos contaminantes críticos, ou seja, as substâncias responsáveis pelos maiores riscos, é importante pois esta será uma das principais informações utilizadas na etapa de intervenção, sendo o principal alvo das ações remediadoras. A partir do estudo realizado, constatou-se que as ferramentas indicaram diferentes substâncias críticas. Os maiores riscos nas simulações com as planilhas da CETESB foram verificados para o TCE. Em oposição, o cenário crítico o na aplicação do RISC5 foi associado com o PCE. Dessa maneira, verificou-se que os parâmetros específicos das substâncias de interesse influenciaram também no resultado final das avaliações realizadas.

\section{Concentrações Máximas Aceitáveis e Metas de Intervenção}

As planilhas da CETESB apresentaram como resultado da avaliação de risco simulada concentrações máximas aceitáveis para cada substância, efeito adverso (carcinogênico e não carcinogênico) e via de exposição avaliados de maneira individual, e independentemente do cenário representar risco inaceitável. Dentre elas, foram selecionadas para compor as metas de remediação apenas as menores concentrações. Nota-se que não foram quantificadas CMA protetivas de um cenário considerando os riscos cumulativos de todas as vias analisadas.

O RISC5 apresentou apenas uma CMA por substância química, sendo esta a mais restritiva entre os riscos carcinogênicos e não carcinogênicos e vias de exposição analisados. Entretanto, para o presente estudo de avaliação de risco utilizando o RISC5 como ferramenta auxiliadora da quantificação de resultados, nenhum dos cenários avaliados foi classificado como com risco inaceitável. Portanto, não foi selecionada nenhuma CMA como meta de remediação.

$\mathrm{Na}$ Tabela 9 são apresentadas as CMA mais restritivas por composto químico e por tipo de risco, no caso das simulações com as planilhas da CETESB, a CMA destacada refere-se a meta para a etapa de remediação.

Na aplicação da ferramenta Planilhas da CETESB na área de estudo, o TCE foi verificado como único composto crítico e possível causador de efeitos adversos. A meta de remediação proposta seria a concentração de $43 \mu \mathrm{g} / \mathrm{L}$, entretanto, considera-se esse valor próximo ao valor orientador de investigação do CONAMA (Brasil, 2009) e padrão de potabilidade da água estabelecido pela Portaria de Potabilidade (Brasil, 2011), de 20 mg/L. Nota-se ainda que os valores de investigação do CONAMA são geralmente baseados em dados da Organização Mundial de Saúde (OMS) e representam concentrações obtidas por meio de avaliações de risco de cenários genéricos de contaminação considerando a ingestão da água subterrânea. 
Tabela 9. Concentrações Máximas Aceitáveis

\begin{tabular}{c|c|c}
\hline \multicolumn{2}{c}{ PCE (mg/L) } \\
\hline Efeito /Ferramenta & Planilhas da CETESB & RISC5 \\
\hline Carcinogênico & RA & RA \\
\hline Não carcinogênico & RA & \\
\hline \multicolumn{2}{|c|}{ TCE (mg/L) } \\
\hline Efeito / Ferramenta & Planilhas da CETESB & RISC5 \\
\hline Carcinogênico & 0,379 & \multirow{2}{*}{ RA } \\
\hline Não carcinogênico & $\mathbf{0 , 0 4 3}$ &
\end{tabular}

RA: risco aceitável

\section{Gerenciamento dos riscos à saúde humana}

Considerando a aplicação das Planilhas da CETESB no caso em estudo, a CMA mais restritiva para o cenário envolvendo inalação em ambiente fechado de vapores provenientes da pluma de contaminação na área de interesse está relacionada a efeitos não carcinogênicos do composto TCE. Dessa forma, os efeitos adversos estão sujeitos a se manifestarem a partir de exposições rápidas na área contaminada. Entretanto, conforme o modelo conceitual da área, o local encontra-se atualmente inativo, e a ocupação residencial ocorrerá apenas quando da mudança do uso do terreno no futuro. Ainda assim, a comunicação sobre o risco avaliado às autoridades deve ser realizada.

Em relação as medidas de intervenção voltadas para a efetiva remediação da contaminação, faz-se necessária a avaliação da aplicabilidade da CMA proposta de $43 \mu \mathrm{g} / \mathrm{L}$ para o TCE. Como apresentado anteriormente, esta meta é muito próxima do valor orientador de investigação (VI) do CONAMA (Brasil, 2009) de $20 \mu \mathrm{g} / \mathrm{L}$.

Complementarmente, verificou-se que em termos de abrangência espacial, os riscos foram quantificados para receptores localizados sobre a pluma e, deste modo, a avaliação deve ser expandida considerando também receptores off site. Além disso, uma nova etapa na investigação da área poderia incluir uma nova avaliação de risco. No caso de manter a aplicação da ferramenta, diante da inflexibilidade na alteração de dados toxicológicos e exposicionais, o novo estudo se fundamentaria em uma caracterização mais representativa da contaminação da área de estudo. A nova avaliação também poderia incluir a aplicação da ferramenta RISC5, porém com a atualização dos valores identificados neste estudo como desatualizados.

\section{CONCLUSÕES}

Este estudo comparou duas ferramentas empregadas na avaliação de risco à saúde humana de áreas contaminadas, sendo elas: as planilhas da CETESB e o software RISC5. As ferramentas foram aplicadas para um caso verídico de contaminação do aquífero livre com tetracloroetileno (PCE) e tricloroetileno (TCE). A partir da comparação realizada verificou-se que ambas as ferramentas fundamentam a avaliação de riscos à saúde humana na metodologia RBCA (United States Environmental Protection Agency, 1989), inclusive encontram-se desatualizadas em relação ao método empregado atualmente pelo mesmo órgão em United States Environmental Protection Agency (2009). As principais divergências encontradas foram quanto as informações toxicológicas sobre os compostos avaliados, os parâmetros exposicionais, premissas empregadas nos algoritmos dos modelos matemáticos de transporte, metodologia de quantificação de CMA e flexibilidade na inserção de dados.

Os resultados das simulações de avaliações de risco utilizando o software RISC5 indicaram riscos aceitáveis para todos os cenários avaliados. Já a aplicação das Planilhas da CETESB para a avaliação de riscos e definição de metas de intervenção indicaram o composto TCE e o receptor criança exposto em ambiente fechado como cenário crítico. Entretanto, a meta estabelecida foi considerada impraticável visto ser muito próximo do próprio limite estabelecido na legislação vigente, Resolução CONAMA n⿳亠口冋. 420/2009 (Brasil, 2009).

Diante do exposto, concluiu-se que conforme o modelo conceitual da área e substâncias de interesse objetos de avaliação de risco à saúde humana, a escolha de determinada ferramenta pode influenciar no resultado final da avaliação, inclusive nas etapas seguintes do gerenciamento de áreas contaminadas. Dentre as ferramentas avaliadas, as planilhas da CETESB são mais simples e rápidas de serem aplicadas, visto suas limitações e restrições de cenários, e também foi aquela que quantificou 
maiores risco, sendo favorável à segurança da população exposta a contaminação. Porém, devido a meta proposta para a etapa de intervenção ser extremamente conservadora seriam recomendados novos estudos de investigação da área. A aplicação do software RISC5 é mais complexa, porém, atende uma variedade maior de casos de contaminação. 0 uso desta ferramenta sem verificação e atualização de dados padrão pode ocasionar estudos não representativos da área e não confiáveis em termos de dados toxicológicos.

\section{REFERÊNCIAS}

Agency for Toxic Substances and Disease Registry - ATSDR. (2020a) Toxicological profile for Trichloroethylene (TCE). Atlanta, GA: U.S. Department of Health and Human Services, Public Health Service. Recuperado em 23 de abril de 2020, de http://tiny.cc/dy3eoz

Agency for Toxic Substances and Disease Registry - ATSDR. (2020b) Toxicological profile for Tetrachloroethylene. Atlanta, GA: U.S. Department of Health and Human Services, Public Health Service. Recuperado em 23 abril 2020, de http://tiny.cc/7z3eoz

Akvoplan (2009). Relatório de investigação detalhada. Curitiba.

American Society for Testing and Materials - ASTM (2012) E1739-95: Risk-based corrective action applied at petroleum release site. West Conshohocken: ASTM.

American Society for Testing and Materials - ASTM. (2015) E2081-00: Standard Guide for Risk-Based Corrective Action. West Conshohocken: ASTM.

Araújo-Moura, A. A. C. D., \& Caffaro Filho, R. A. (2015). Panorama do gerenciamento de áreas contaminadas no Brasil após a Resolução CONAMA 420/09. Águas Subterrâneas, 29(1), 202-212.

Associação Brasileira de Normas Técnicas - ABNT. (2013a). NBR 16.209: Avaliação de risco a saúde humana para fins de gerenciamento de áreas contaminadas. Rio de Janeiro: ABNT.

Associação Brasileira de Normas Técnicas - ABNT. (2013b). NBR 16.210: Modelo conceitual no gerenciamento de áreas contaminadas - procedimento. Rio de Janeiro: ABNT.

Barros, D., \& Carvalho, D. D. (2012). Utilização da metodologia RBCA em atividades de revenda de combustíveis Estudo de caso no município do Rio de Janeiro. In XVI Congresso Brasileiro de Águas Subterrâneas. São Luís.

Brasil (2009, 28 de dezembro). Resolução no 420, de 28 de dezembro de 2009. Dispõe sobre critérios e valores orientadores de qualidade do solo quanto à presença de substâncias qualidade do solo quanto à presença de substâncias. Diário Oficial [da] República Federativa do Brasil, Brasília. Recuperado em 26 de março de 2017, de https://goo.gl/ZdYV7r

Brasil. Ministério da Saúde (2011, 12 de dezembro). Portaria no 2914, de 12 de dezembro de 2011. Dispõe sobre os procedimentos de controle e de vigilância da qualidade da água para consumo humano e seu padrão de potabilidade. Diário Oficial [da] República Federativa do Brasil, Brasília. Recuperado em 26 de março de 2017, de https://goo.gl/PE9Ud

Cathcart, D. (2014). Análise comparativa de modelos de avaliação de risco à saúde humana para o gerenciamento de áreas contaminadas (Monografia de Graduação). Universidade Federal de Santa Catarina, Florianópolis, p. 168.

Cathcart, D. (2017). Avaliação de risco à saúde humana no gerenciamento de áreas contaminadas e a sua mitigação por meio de medidas de controle. (Monografia). Universidade do Sul de Santa Catarina, Florianópolis.

Chang, S.-H., Kuo, C., Wang, J.-W., \& Wang, K.-S. (2004). Comparison of RBCA and CalTOX for setting risk-based cleanup levels based on inhalation exposure. Chemosphere, 56, 359-367.

Companhia Ambiental do Estado de São Paulo - CETESB \& Deutsche Gesellschaft für Technische Zusammenarbeit - GTZ (2001). Manual de gerenciamento de áreas contaminadas. São Paulo: CETESB.

Companhia Ambiental do Estado de São Paulo - CETESB (2006). Decisão de Diretoria N.o 10/2006/C. São Paulo: CETESB.

Companhia Ambiental do Estado de São Paulo - CETESB (2013). Planilhas para avaliação de risco em áreas contaminadas sob investigação, versão maio 2013. Disponível em: https://goo.gl/U2j1ST. Acesso em: 02 março 2017.

Companhia Ambiental do Estado de São Paulo - CETESB. Diretoria de Controle e Licenciamento Ambiental (2015). Texto explicativo - Relação de áreas contaminadas e reabilitadas no estado de São Paulo. São Paulo: CETESB. 
Companhia Ambiental do Estado de São Paulo - CETESB (2017). Decisão de Diretoria N.ํ38/2017/C. Diário Oficial Estado de São Paulo, São Paulo.

Correia, J. A., Ribeiro, R. C. D. C., \& Lima, C. A. D. (2016). Avaliação de risco à saúde humana dos resíduos gerados no beneficiamento de pegmatitos. In Anais da XXIV Jornada de Iniciação Científica (p. 5). Rio de Janeiro: CETEM, MCTIC.

Coutinho, L. S. D. A. L, Duarte, A. A. A. M., Neves, R. M., Coutinho Neto, B., Maneschy, C. E. A., \& Pinheiro, A. M. G. S (2012). Modelagem do tempo de execução de obras civis: estudo de caso na Universidade Federal do Pará. Ambiente Construído, Porto Alegre, 12(1), 243-256.

Couto, M. L. T. (2006). Atualização dos fatores de exposição e sua influência nos valores de intervenção para solo do estado de São Paulo (Dissertação de Mestrado). Universidade Estadual de Campinas, Campinas.

Cunha, R. C. D. A. (2012). Análise de Risco como Ferramenta para Tomada de Decisões In I Seminário SulBrasileiro de Gerenciamento de Áreas Contaminadas. Porto Alegre: ABES, 3 e 4 setembro 2012. Recuperado em 12 de fevereiro de 2017, de https://goo.gl/BZvHd3

Dias, C. L., Casarini, D. C. P., \& Lemos, M. M. G. (2001). Relatório de estabelecimento de valores orientadores para solos e águas. São Paulo: CETESB.

Eco Reg do Brasil (2011). Plano de remediação. Curitiba: Eco Reg do Brasil.

Eco Reg do Brasil (2017). Relatório de monitoramento ambiental. Curitiba: Eco Reg do Brasil.

Fan, C., Chen, Y., Ma, H., \& Wang, G. (2010). Comparative study of multimedia models applied to the risk assessment of soil and groundwater contamination sites in Taiwan. Journal of Hazardous Materials, 182, 778-786.

Federação das Indústrias do Estado de Minas Gerais - FIEMG. (2017). Gerenciamento de áreas contaminadas: Conceitos e informações gerais. Belo Horizonte: FIEMG. Recuperado em 29 de março de 2017, de https://goo.gl/tNNatz

Gonçalves, J. A. C., \& Lena, J. C. D. (2013). Avaliação de risco à saúde humana por contaminação natural de arsênio nas águas subterrâneas e nos solos da área urbana de Ouro Preto (MG). Revista do Instituto de Geociências, São Paulo, 13(2), 145-148.

Gouvêa Júnior, J. C. R. (2011). Influência dos parâmetros do meio físico sobre as concentrações de referência para intrusão de vapores de BTEX em ambientes fechados (Dissertação de Mestrado). Instituto de Pesquisas Tecnológicas do Estado de São Paulo, São Paulo.

Grimski, D. (2004). Revitalização de áreas degradadas e contaminadas na Alemanha e Europa. In D. Rodrigues, F. E. Alves, \& S. H., Numa. Remediação e revitalização de Áreas Contaminadas. São Paulo: Signus.

Han, L., Qian, L., Yan, J., Liu, R., Du, Y., \& Chen, M. (2016). A comparison of risk modeling tools and a case study for human health risk assessment of volatile organic compounds in contaminated groundwater. Environmental Science and Pollution Research, 23(2), 1234-1245.

Instituto do Meio Ambiente - IMA (2018). Instrução Normativa no 74/2018 - Recuperação de Áreas Contaminadas. Florianópolis.

Johnson, P. C., \& Ettinger, R. A. (1991). Heuristic model for predicting the intrusion rate of contaminant vapors into buildings. Environmental Science \& Technology, Houston, 25(8), 1445-1452.

Joussef, K. L. (2013). Influência da taxa de dose potencial variável em áreas contaminadas no cálculo de risco à saúde humana (Dissertação de mestrado). Centro Tecnológico, Universidade Federal de Santa Catarina, Florianópolis.

Maximiano, A. (2011). Avaliação de Risco à Saúde Humana no Gerenciamento de Áreas Contaminadas. In Seminário FEAM - Gerenciamento de Áreas Contaminadas em Minas Gerais. Belo Horizonte: FEAM.

Michels, C., Schneider, M. R., Coelho, J. I. E., \& Corseuil, H. X. (2004). Avaliação de risco à saúde humana em terminais de armazenamento de petróleo e derivados: estudos de casos. In Anais do Suplemento XIII Congresso Brasileiro de Águas Subterrâneas (pp. 1-12). Cuiabá: Associação Brasileira de Águas Subterrânea, 2004.

Moraes, S. L. D., Teixeira, C. E., \& Maximiano, A. M. D. S. (2004). Guia de elaboração de planos de intervenção para o gerenciamento de áreas contaminadas. São Paulo: Instituto de Pesquisas Tecnológicas do Estado de São Paulo.

Nascimento, G. G. C. C. (2015). Análise de risco à saúde humana em área de contaminação ambiental no município de Adrianópolis, Vale do Ribeira, PR. Campinas: Instituto de Geociências, Universidade Estadual de Campinas. 283 p. 
Pankow, J. F., \& Cherry, J. A. (1996). Dense chlorinated solvents and other DNAPLs in groundwater: History, Behavior, and Remediation. Portland: Waterloo Press.

Regens, J. L., Obenshain, K. R., Gunter, J. T., \& Miller, V. (2000). Modeling radiological risks to human health from contaminated soils: comparing MEPAS, MMSOILS, and RESRAD. Human and Ecological Risk Assessment, 6(5), 777-788.

Sanberg, E., Augustin, S., Gocks, N. R. A., Quadros, P. S., Tizatto, R., \& Vedana, L. A. (2015). A Avaliação de riscos à saúde humana como ferramenta para gerenciamento ambiental no Brasil. In Anais do XV Congresso Brasileiro de Geologia de Engenharia Ambiental. Bento Gonçalves: ABGE, 2015.

Serviço Nacional de Aprendizagem Industrial - SENAI. (2008). Relatório de investigação confirmatória. Curitiba: SENAI-CIC/CETSAM.

Song, S. (2004). 0 papel da análise de risco na remediação de áreas contaminadas. In E. Moeri, R. Coelho \& A. Marker. Remediação e Revitalização de Áreas Contaminadas. São Paulo: Signus Editora.

Spence, L., \& Walden, T. (2013). RISC5 user's guide. [S.I.]: Spence Environmental Engineering e British Petroleum.

Squissato, B. V. A. D. O. (2012). Aplicação de sistema de informações geográficas para avaliação de risco à saúde humana (Dissertação de mestrado). Instituto de Geociências e Ciências Exatas, Universidade Estadual Paulista, Rio Claro, p. 110.

Teixeira, C. E., Motta, F. G., \& Moraes, S. L. D. (2016). Panorama do setor de gerenciamento de áreas contaminadas no Brasil ("panorama GAC"). São Paulo: Instituto de Pesquisas Tecnológicas do Estado de São Paulo.

Toledo, M. C. (2016). Avaliação probabilística de riscos à saúde humana em área contaminada por organoclorados (Dissertação de mestrado). Universidade de São Paulo, São Paulo.

United States Environmental Protection Agency - U.S. EPA. (1989). Risk assessment guidance for superfund volume I human health evaluation manual (part A). Washington: U.S.EPA.

United States Environmental Protection Agency - U.S. EPA. (2009). Risk assessment guidance for superfund volume I: human health evaluation manual (part F, supplemental guidance for inhalation risk assessment). Washington: U.S.EPA.

United States Environmental Protection Agency - U.S. EPA. (2011). Exposure factor handbook: 2011 Edition (p. 1436). Washington: National Center for Environmental Assessment.

United States Environmental Protection Agency - U.S. EPA. (2017a). Regional screening levels (RSLs), Recuperado em 01 de outubro de 2017, de https://goo.gl/LATyFM.

United States Environmental Protection Agency - U.S. EPA. (2017b). Contaminants at superfund sites, Recuperado em 08 de abril de 2017, de https://goo.gl/wKnVyE.

\section{Contribuição:}

Mariana Barbosa Druszcz: elaboração do manuscrito com base na pesquisa realizada como requisito parcial à obtenção do grau de Mestre em Meio Ambiente Urbano e Industrial, no Programa de Mestrado em Meio Ambiente Urbano e Industrial, da Universidade Federal do Paraná em parceria com o SENAI/PR e a Universität Stuttgart, Alemanha

Jörg Wolfgang Metzger: direcionamento do trabalho e orientação

Marielle Feilstrecker: direcionamento do trabalho, orientação e correção 